\title{
Histological Studies Of The Effects Of Monosodium Glutamate On The Testis Of Adult Wistar Rats
}

\author{
A Eweka, F Om'Iniabohs
}

\section{Citation}

A Eweka, F Om'Iniabohs. Histological Studies Of The Effects Of Monosodium Glutamate On The Testis Of Adult Wistar Rats. The Internet Journal of Urology. 2007 Volume 5 Number 2.

\begin{abstract}
Histological effects of Monosodium glutamate (MSG) commonly used as food additive on the Testis of adult Wistar rats were carefully studied. The rats of both sexes $(n=24)$, average weight of $185 \mathrm{~g}$ were randomly assigned into two treatments $(n=16)$ and control $(n=8)$ groups. The rats in the treatment groups received $3 g$ and $6 \mathrm{~g}$ of MSG thoroughly mixed with their feeds for fourteen days, while the control rats received equal amounts of feeds without MSG added. The rats were fed with growers' mash purchased from Edo Feeds and Flour Mill Ltd, Ewu, Edo State and were given water liberally. The rats were sacrificed on day fifteen of the experiment. The testis was carefully dissected out and quickly fixed in $10 \%$ buffered formaldehyde for routine histological study after H\&E method.

The histological findings after H\&E methods indicated that the treated sections of the testis showed some cystic degenerative changes, with some vacuolations appearing in the stroma when compared to the control sections. There were atrophic and degenerative changes with the group that received $6 \mathrm{~g}$ of MSG more severe. These findings indicate that MSG consumption may have a deleterious effect on the sertoli cells and leydig cells of the testis and may probably have adverse effects on spermatogenesis, spermiogenesis and testosterone production in adult male Wistar rats. This is in consonance with previous work done and reported by Onakewoh et al.
\end{abstract}

\section{INTRODUCTION}

Monosodium glutamate (MSG) otherwise known as AJINO-MOTO is the sodium salt of glutamic acid. Glutamate is one of the most common amino acids found in nature and is the main component of many proteins and peptides of most tissues. Monosodium glutamate contains $78 \%$ of glutamic acid, $22 \%$ of sodium and water ${ }_{1}$. Glutamate is also produced in the body and plays an essential role in human metabolism. It is a major component of many protein-rich food products such as meat, fish, milk and some vegetables ${ }_{2}$

MSG is produced in many countries around the world through a fermentation process of molasses from sugar cane or sugar beets, as well as starch and corn sugar. In this fermentation process, bacteria, which may be genetically modified, are grown aerobically in a liquid nutrient medium. These bacteria have the ability to synthesize glutamic acid outside of their cell membranes and excrete it into the medium to accumulate there ${ }_{2,3}$. When MSG is added to food, it provides a flavoring function similar to the naturally occurring free glutamate: which differ from the four classic tastes of sweet, sour, salty and bitter.
In Nigeria, most communities and individuals often use Monosodium glutamate as a bleaching agent for the removal of stains from clothes. There is a growing apprehension that its bleaching properties could be harmful or injurious to the body, or worse still inducing terminal diseases in consumers when ingested as a flavor enhancer in food. Despite evidence of negative consumer response to MSG, reputable international organizations and nutritionist have continued to endorse Monosodium glutamate, and reiterate that it has no adverse reactions in humans. The Directorate and Regulatory Affairs of Food and Drug Administration and Control (FDA $\& C$ ) in Nigeria, now NAFDAC has also expressed the view that MSG is not injurious to health ${ }_{4}$. The Food and Drug Administration (FDA) of the United States reports that Monosodium glutamate is safe and that it should be maintained on the "Generally Recognized as Safe" (GRAS)list of foods; being listed on food labels as a "Flavoring" or "hydrolyzed vegetable protein". MSG is thus reportedly permitted as a safe food additive that needs no specified average, daily intake or an upper limit intake requirement ${ }_{1}$.

Through its stimulation of the orosensory receptors and by improving the palatability of meals, MSG influences the 
appetite positively, and induces weight gain ${ }_{5}$. Despite its taste stimulation and improved appetite enhancement, reports indicate that MSG is toxic to human and experimental animals ${ }_{6}$.

In 1968, the first published report of an adverse reaction to Monosodium glutamate appeared in the New England Journal of Medicine where it was reported that Monosodium glutamate was neurotoxic; killing brain cells, causing retinal degeneration, endocrine disorder and also associated with a number of pathological conditions such as addiction, stroke, epilepsy, brain trauma, neuropathic pain, schizophrenia, anxiety, depression, degenerative disorders such as Parkinson's disease, Alzheimer's disease, Huntington's disease, and amyotrophic lateral sclerosis ${ }_{1}$. The toxic effect of MSG was reported by the work done on the testis, causing significant oligozoospermia and increase abnormal sperm morphology in a dose-dependent fashion in male Wistar rats 7. It has also being established that MSG may be implicated in cases of male infertility as it causes testicular hemorrhage, degeneration and alteration of sperm cell population and $\operatorname{morphology}_{8}$.

The testes are paired organs in males lying in the scrotal sac, and functions in the production of spermatozoa and secretion of male sex hormones, principally testosterone ${ }_{9}$. Since MSG causes significant oligozoospermia and increase abnormal sperm morphology in a dose-dependent fashion in male Wistar rats, it is relevant to investigate some of its histological effects on the testis. It is probable that the adverse effects of MSG may affect the normal physiological action of the testis and hence this investigation.

\section{MATERIALS AND METHODS}

ANIMALS: Twenty four (24) adult male Wistar rats with average weight of $185 \mathrm{~g}$ were randomly assigned into three groups $\mathrm{A}, \mathrm{B}$ and $\mathrm{C}$ of $(\mathrm{n}=8)$ in each group. Groups $\mathrm{A}$ and $\mathrm{B}$ of $(n=16)$ serves as treatments groups while Group $C(n=8)$ is the control. The rats were obtained and maintained in the Animal Holdings of the Department of Anatomy, School of Basic Medical Sciences, University of Benin, Benin city, Nigeria. They were fed with growers' mash obtained from Edo feed and flour mill limited, Ewu, Edo state) and given water liberally. The rats gained maximum acclimatization before actual commencement of the experiment. The Monosodium glutamate ( $3 \mathrm{~g}$ / sachet containing $99+\%$ of MSG) was obtained from Kersmond grocery stores, Uselu, Benin City.

MONOSODIUM GLUTAMATE ADMINISTRATION: The rats in the treatment groups (A and $\mathrm{B}$ ) were given $3 \mathrm{~g}$ and $6 \mathrm{~g}$ of MSG, thoroughly mixed with the growers' mash, respectively. The control @ group received equal amount of feeds (growers' mash) without MSG added for fourteen days. The rats were sacrificed on the fifteenth day of the experiment. The testis was quickly dissected out and fixed in $10 \%$ buffered formaldehyde for routine histological techniques. The $3 \mathrm{~g}$ and $6 \mathrm{~g}$ MSG doses were chosen and extrapolated in this experiment based on the indiscriminate use here in Nigeria due to its palatability. The two doses were thoroughly mixed with fixed amount of feeds $(550 \mathrm{~g})$ in each group, daily.

HISTOLOGICAL STUDY: The tissue were dehydrated in an ascending grade of alcohol (ethanol), cleared in xylene and embedded in paraffin wax. Serial sections of 6 microns thick were obtained using a rotatory microtome. The deparaffinized sections were stained routinely with haematoxyline and eosin. Photomicrographs of the desired sections were made for further observations.

\section{RESULTS}

The control sections of the testis showed normal histological features with the cross section of the convoluted seminiferous tubules showing stratified epithelium which consists of two distinct populations of cells; the spermatogenic cells and the sertoli cells. The leydig cells within the supporting tissues in the interstitial spaces between the tubules were all visible. (Figure1).

The treatment sections of the testis showed some histological changes that were at variance with those obtained in the control. There was evidence of cystic degenerative changes, some intercellular vacuolations appearing in the stroma when compared to the control sections. There were atrophic and degenerative changes with the group that received $6 \mathrm{~g}$ of MSG more severe (Figure $2 \&$ $3)$. 


\section{Figure 1}

Figure 1: Control section of the testis (Seminiferous tubules) (Mag. x400).

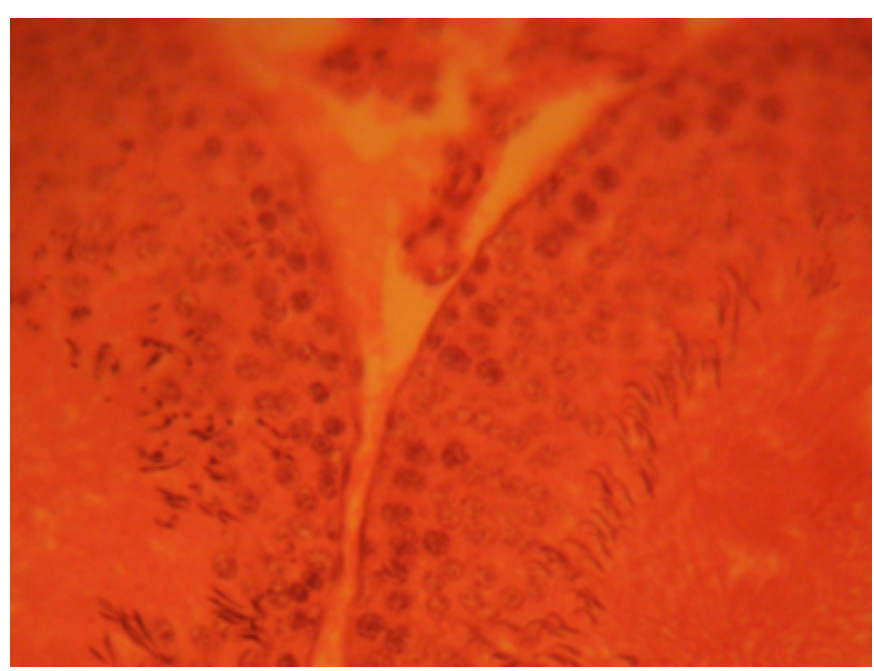

\section{Figure 2}

Figure 2: Treatment section of the testis (Seminiferous tubules) (3g MSG) (Mag. x400)

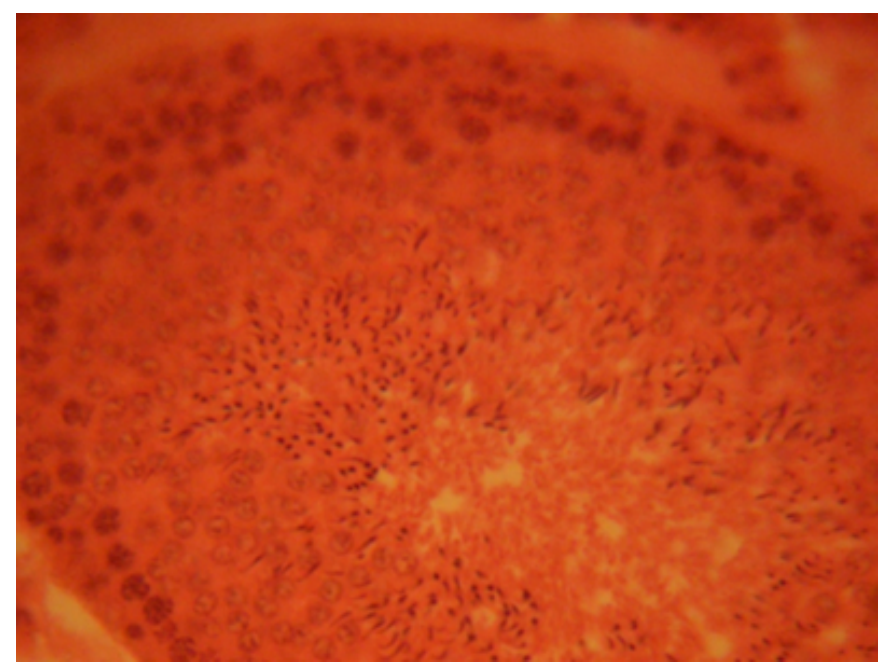

\section{Figure 3}

Figure 3: Treatment section of the testis (Seminiferous tubules) (6g MSG).(Mag. x400)

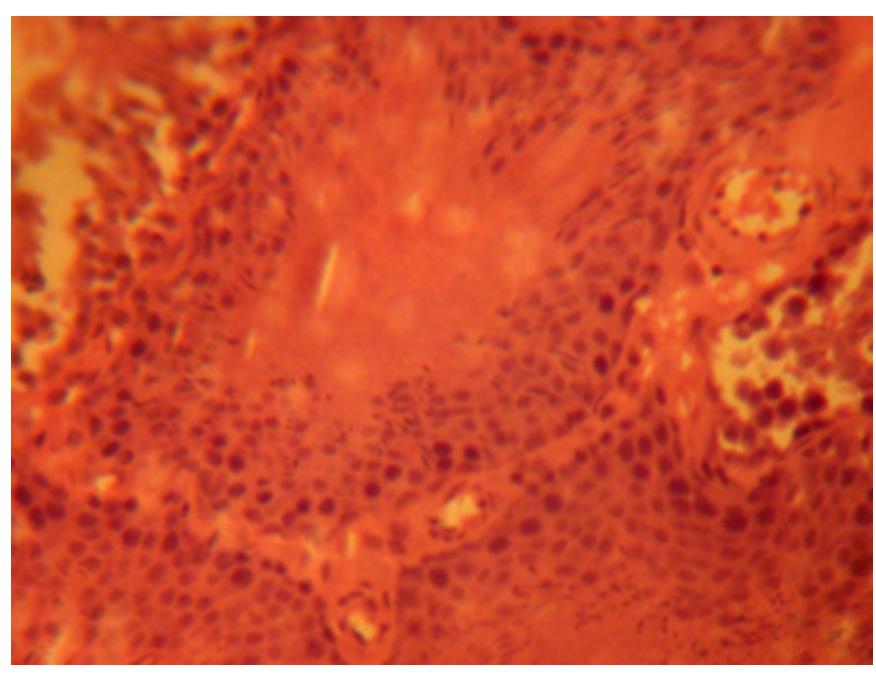

\section{DISCUSSION}

The results $(\mathrm{H} \& \mathrm{E})$ reactions showed cystic degenerative changes, with some intercellular vacuolations appearing in the stroma of the seminiferous tubules when compared to the control sections. There were atrophic and degenerative changes with the group that received $6 \mathrm{~g}$ of MSG more severe. The vacuolations observed in the stroma of the treated testis may be due to MSG interference. The toxic effects of MSG on the testis observed in this experiment may underline the possible effects already reported ${ }_{7,8}$. The actual mechanism by which MSG induced cellular degenerative and atrophic changes observed in this experiment needs further investigation.

Degenerative changes have been reported to result in cell death, which is of two types, namely apoptotic and necrotic cell death. These two types differ morphologically and biochemically ${ }_{11}$. Pathological or accidental cell death is regarded as necrotic and could result from extrinsic insults to the cell such as osmotic, thermal, toxic and traumatic effects ${ }_{12}$. In this experiment MSG could have acted as toxins to the cells of the testis. The process of cellular necrosis involves disruption of membrane's structural and functional integrity which was also a landmark of this experiment. In cellular necrosis, the rate of progression depends on the severity of the environmental insults.

The greater the severity of insults, the more rapid the progression of neuronal injury ${ }_{13}$. The principle holds true for toxicological insults to the brain and other organs ${ }^{14}$. It may be inferred from the present results that prolonged intake and higher doses of MSG as been taken indiscriminately resulted 
in increase toxic effects on the testis.

\section{CONCLUSION AND RECOMMENDATION}

The results obtained in this study following the administration of $3 \mathrm{~g}$ and $6 \mathrm{~g}$ per day of MSG to adult male Wistar rats causes cystic degeneration, vacuolations and degenerative and atrophic changes, worse in the high dose. In inference these confirm earlier report that MSG may be a cause of male infertility. It is recommended that further studies be carried out to corroborate these findings.

\section{References}

1. Samuels A. The Toxicity/Safety of MSG; A study in suppression of information. Accountability in Research. 6(4): 259-310, 1999.

2. IFIC Review of Monosodium glutamate: Examining the myths, 1994.

3. Leung A, Foster S. Encyclopaedia of common natural ingredient used in

food, drugs and cosmetics. New York. Wiley 1996, pp373-375

4. Okwuraiwe PE. The role of food and drug administration and control

(FDA\&C) in ensuring the safety of food and food ingredients: A symposium

held at Sheraton Hotel, Lagos. 1st Sept.1992: 6-15.

5. Rogers PP, Blundell JE. Umani and appetite: Effects of monosodium

glutamate on hunger and food intake in human subjects.

Phsiol. Behav.

1990: 486:801-4.

6. Belluardo M, Mudo G, Bindoni M. Effect of early destruction of the

mouse arcuate nucleus by MSG on age dependent natural

killer activity.

Brain Res.1990, 534:225-333

7. Onakewhor JUE, Oforofuo IAO, Singh SP. Chronic administration of

Monosodium glutamate induces oligozoospermia and glycogen

accumulation in Wister rat testes. Afri J. Reprod. Health 1998; 2(2):190

197.

8. Oforofuo IAO, Onakewhor JUE, Idaewor PE. The effect of chronic

administration of MSG on the histology of the Adult wister rat testes:

Bioscience Res. Comm. Vol. 9, No. 2, June 30, 1997.

9. Young B, Heath JW. Wheater's Functional Histology- A text and colour

atlas, Fourth Edition. Churchill Livingstone. 2000. pp. 328-340.

10. Wyllie A H. Glucocorticoid-induced thymocyte apoptosis is associated with

endogenous endonuclease activation. Nature, London 1980 , 284:555-556.

11. Farber J L, Chein K R, Mittnacht S. The pathogenesis of irreversible cell

injury in ischemia. American Journal of Pathology

1981,102:271-281.

12. Ito U, Sparts M, Walker JT, Warzo. Experimental cerebral ischemia in

Magolian gerbils (1) Light microscope observations. Acta Neurophatology USA 1975, 32:209-223.

13. Martins LJ, Deobler JA, Shih T, Anthony A.

Cytophotometric analysis of

thalamic neuronal RNA in some intoxicated rats. Life Sci.1984, 35 1593-

1600 . 


\section{Author Information}

\section{A.O. Eweka}

Department Of Anatomy, School Of Basic Medical Sciences, College Of Medical Sciences, University Of Benin

\section{F.A.E. Om'Iniabohs}

Department Of Anatomy, School Of Basic Medical Sciences, College Of Medical Sciences, University Of Benin 